\title{
Chapter 5 \\ The Complex Mixture, Fate and Toxicity of Chemicals Associated with Plastic Debris in the Marine Environment
}

\author{
Chelsea M. Rochman
}

\begin{abstract}
For decades we have learned about the physical hazards associated with plastic debris in the marine environment, but recently we are beginning to realize the chemical hazards. Assessing hazards associated with plastic in aquatic habitats is not simple, and requires knowledge regarding organisms that may be exposed, the exposure concentrations, the types of polymers comprising the debris, the length of time the debris was present in the aquatic environment (affecting the size, shape and fouling) and the locations and transport of the debris during that time period. Marine plastic debris is associated with a 'cocktail of chemicals', including chemicals added or produced during manufacturing and those present in the marine environment that accumulate onto the debris from surrounding seawater. This raises concerns regarding: (i) the complex mixture of chemical substances associated with marine plastic debris, (ii) the environmental fate of these chemicals to and from plastics in our oceans and (iii) how this mixture affects wildlife, as hundreds of species ingest this material in nature. The focus of this chapter is on the mixture of chemicals associated with marine plastic debris. Specifically, this chapter discusses the diversity of chemical ingredients, byproducts of manufacturing and sorbed chemical contaminants from the marine environment among plastic types, the role of marine plastic debris as a novel medium for environmental partitioning of chemical contaminants in the ocean and the toxic effects that may result from plastic debris in marine animals.
\end{abstract}

Keywords Monomers and additives - Persistent organic pollutants - Metals • Cocktail of contaminants - Toxicity

C.M. Rochman ( $\square)$

Aquatic Health Program, School of Veterinary Medicine,

University of California, Davis, CA, 95616, USA

e-mail: cmrochman@ucdavis.edu 


\subsection{Introduction}

Since the Industrial Revolution, there has been an exponential increase in the production and use of chemical substances, such that now the amount of chemicals produced annually is more than $400 \times$ greater than the amount produced annually four decades ago (Binetti et al. 2008). Among these chemical substances are several of the ingredients used in the manufacturing of plastics (Lithner et al. 2011). This increasing production and use is inevitably accompanied by an increase in waste, creating a challenge for waste management. Several mechanisms have recently been developed for managing waste, including landfill, wastewater treatment and recycling. Still, these mechanisms are not $100 \%$ efficient and/or do not yet exist in several locations worldwide. The marine environment, residing at the end of most watersheds, is thus often the ultimate sink for many of these substances, including plastic, when not properly managed. As a consequence, plastic debris and many chemical contaminants are detected in our oceans globally.

In parallel with chemicals, the production rate of plastics has increased exponentially, from 0.5 million tons produced annually in 1950 to greater than 299 million tons produced annually today (Thompson et al. 2009; PlasticsEurope 2013). Of this material, less than $50 \%$ was accounted for in the waste stream in 2012 (Rochman et al. 2013a). While some of these products may be still in use, others become litter. Today, marine plastic pollution has become ubiquitous and is reported globally from the ocean surface (Thompson et al. 2004; Goldstein et al. 2013; Eriksen et al. 2014; Law et al. 2014; Desforges et al. 2014) to the deep sea (Goldberg 1997; Galgani et al. 2000).

For decades we have learned about the physical hazards associated with this pollution in the marine environment (Laist 1987), but recently we are beginning to realize the chemical hazards. Marine plastic debris is associated with a 'cocktail of chemicals', including chemicals added or produced during manufacturing (Lithner et al. 2011) and those present in the marine environment that accumulate onto the debris from surrounding seawater (Mato et al. 2001; Ogata et al. 2009). This begs several questions regarding: (i) the complex mixture of chemical substances associated with marine plastic debris, (ii) the environmental fate of these chemicals to and from plastics in our oceans and (iii) how this mixture affects wildlife, as hundreds of species ingest this material in nature (CBD 2012). The focus of this chapter is on the mixture of chemicals associated with marine plastic debris. Specifically, this chapter discusses the diversity of chemical ingredients, byproducts of manufacturing and sorbed chemical contaminants from the marine environment, the role of marine plastic debris as a novel medium for environmental partitioning of chemical contaminants in the ocean and the toxic effects that may result from plastic debris in marine animals.

\subsubsection{Plastic Marine Debris: A Complex Mixture of Chemicals}

Marine plastic debris is associated with a complex mixture of chemicals, including those that are ingredients of the plastic material (e.g. monomers and additives), 


\section{Cocktail of Contaminants}

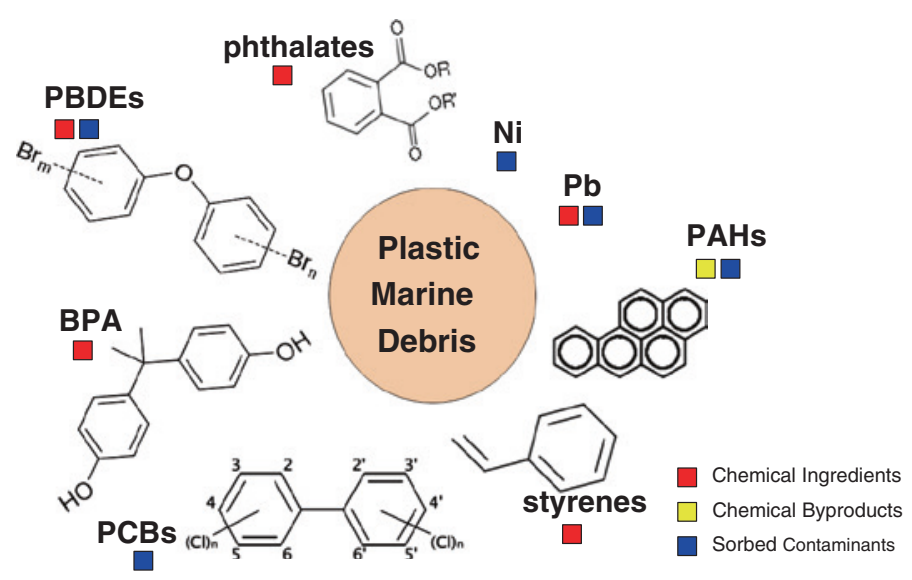

Fig. 5.1 Cocktail of contaminants associated with marine plastic debris. Contaminants associated with marine debris include chemical ingredients (red squares), byproducts of manufacturing (yellow squares) and those that accumulate from surrounding ocean water in the marine environment (blue squares)

byproducts of manufacturing (e.g. chemicals composed during the combustion of the raw material petroleum) and chemical contaminants in the ocean that accumulate on plastic when it becomes marine debris (e.g. persistent organic pollutants (POPs) and metals). There is evidence that this mixture, or 'cocktail of contaminants' (Fig. 5.1; Rochman 2013), can be bioavailable to whales (Fossi et al. 2012, 2014), basking sharks (Fossi et al. 2014), seabirds (Teuten et al. 2009; Tanaka et al. 2013; Lavers et al. 2014), amphipods (Chua et al. 2014), crickets (Gaylor et al. 2012), lugworms (Arenicola marina) (Besseling et al. 2013; Browne et al. 2013) and fish (Rochman et al. 2013b) upon ingestion. This is a cause for concern, as the (USEPA 2013) and the European Union (European Commission 2014) list several of these chemicals as priority pollutants because they are persistent, bioacummulative and/or toxic. In fact, of the chemicals listed as priority pollutants by the US EPA, $78 \%$ are associated with marine plastic debris (Rochman et al. 2013a). This section discusses the complex mixture of chemicals associated with marine plastic debris, including those that originate from manufacturing, that accumulate from surrounding ocean water and how this mixture may vary according to the location where plastic is discarded and the plastic type.

\subsubsection{Plastics and Their Chemical Ingredients}

There are several different types of plastics manufactured into a diversity of products. Each is produced by polymerizing individual monomers, forming the backbone of the polymer. These are made using solvents and other chemicals that may be used as initiators and catalysts. Next, several additives (e.g. flame retardants, 
stabilizers, pigments and fillers) are included to give the plastic certain characteristics (e.g. flexibility, strength and color; OECD 2004; Lithner et al. 2011). Such chemicals, in addition to byproducts, may be released during production, use and disposal of the product, several of which can be harmful (Oehlmann et al. 2009; Teuten et al. 2009; Halden et al. 2010; Lithner et al. 2011; Papaleo et al. 2011). According to United Nations and European Union frameworks, $>50 \%$ of the plastics that are produced are hazardous based upon their constituent monomers, additives and byproducts (Lithner et al. 2011).

The backbone structure, derived from long chains of monomers, are thought to be biochemically inert due to their large molecular size (Teuten et al. 2009; Lithner et al. 2011). Still, several of these are shown to have harmful effects (Xu et al. 2004; Halden et al. 2010; Lithner et al. 2011). Bisphenol A, used in the production of polycarbonate, can have endocrine disrupting effects (Oehlmann et al. 2009; Crain et al. 2007; Halden et al. 2010) and the styrene and polyvinyl chloride monomer, used in the production of polystyrene and polyvinyl chloride (PVC), can be carcinogenic and/or mutagenic (Papaleo et al. 2011; Xu et al. 2004; Lithner et al. 2011) and are listed as toxic substances by the USEPA, ATSDR and OSPAR.

Several of the chemicals used in the production process, including solvents, suspension aids, surfactants, initiators, catalysts and byproducts can also be harmful upon exposure (Lithner et al. 2011). For example, tributyltin (shown to cause endocrine disruption in molluscs; Oehlmann et al. 1996) and copper chloride (shown to have developmental effects on fish; Anderson et al. 1991) are added as catalysts during production (Lithner et al. 2011) and several solvents (shown to be carcinogenic; Lynge et al. 1997) are used in the production process (e.g. methanol, cyclohexane and 1,2-dichlorobenzene; Braun et al. 2005; Gowariker et al. 2003; Lithner et al. 2011).

The additive ingredients include plasticizers, antioxidants, flame-retardants and UV-stabilizers. In some cases, the ingredients make up a large proportion of the plastic product. Phthalates may constitute up to $50 \%$ of the total weight of PVC plastics (Bauer and Herrmann 1997). The use of additives is also not equally distributed across plastic types-PVC requires the most additives accounting for $73 \%$ of the world production of additives by volume, followed by polyethylene and polypropylene (10\% by volume) and styrenics (5\% by volume) (Lithner et al. 2011). Several of these have been recognized or suggested to be hazardous, including the brominated flame retardants (PBDEs), phthalate plasticizers and lead heat stabilizers (Oehlmann et al. 2009; Halden et al. 2010; Lithner et al. 2011).

Finally, some hazardous chemicals may be produced as byproducts during manufacturing. PAH formation occurs during the production cycle of polystyrene (Zabaniotou and Kassidi 2003; Kwon and Castaldi 2008). Residuals of these chemicals may be difficult to remove, therefore carry over into the plastic product and become one of the many chemicals in the cocktail of contaminants associated with marine plastic debris. Thus, when considering the hazards associated with plastic debris, it is important to consider polymer type. 


\subsubsection{The Accumulation of Chemicals on Plastic Debris in the Marine Environment}

Because of their physical and chemical properties, plastics accumulate a complex mixture of chemical contaminants present in the surrounding seawater (Mato et al. 2001; Teuten et al. 2007, 2009; Rochman et al. 2013c; Holmes et al. 2012; Engler 2012), adding to the cocktail of chemicals already present from manufacturing. As a result of widespread global contamination of chemical contaminants (Ogata et al. 2009; Ross and Birnbaum 2010) and plastic debris (Thompson et al. 2004; Barnes et al. 2009; Browne et al. 2011), marine plastic debris is recovered globally with measurable amounts of POPs (e.g. polychlorinated biphenyls (PCBs), PAHs and PBDEs) and other persistent bioaccumulative and toxic substances (PBTs) (e.g. halogenated flame retardants, pesticides and nonylphenol; Mato et al. 2001; Endo et al. 2005; Ogata et al. 2009; Hirai et al. 2011; Heskett et al. 2012; Rios et al. 2010) and metals (e.g. lead, copper and cadmium; Ashton et al. 2010; Holmes et al. 2012; Rochman et al. 2014a).

PBTs, which include those listed as POPs by the Stockholm Convention, generally have a low water-solubility (i.e. are hydrophobic) and tend to partition out of the water column and onto another environmental matrix with similar hydrophobic properties (e.g. sediment, organic matter); thus, when PBTs encounter plastic debris they tend to sorb to this material (Engler 2012). Thus, it is not surprising that an early study reported PCBs on marine plastic debris (Carpenter and Smith 1972) or that plastics are used as passive samplers to quantify PBTs in aquatic environments (Huckins et al. 1993; Lohmann 2012).

Today, the accumulation of PBTs on plastic debris is unequivocal. Global samples show the presence of PBTs on plastic debris collected from coastal beaches (Van et al. 2011; Heskett et al. 2012; Fries et al. 2012; Fisner et al. 2013; Antunes et al. 2013) all the way to the remote open-ocean (Rios et al. 2007, 2010; Hirai et al. 2011). As such, plastic pre-production pellets, a recognizable component of marine debris, are now used to examine the global pattern of PBTs (Ogata et al. 2009; Takada et al. 2006), acting as passive samplers and providing baseline information regarding PBT contamination in the ocean. International Pellet Watch leads this effort, collecting plastic pellets globally and measuring the concentrations of various PBTs sorbed to plastic debris (Takada et al. 2006; Ogata et al. 2009; see also Fig. 5.3 in Hidalgo-Ruz and Thiel 2015 in this volume).

The presence of organic chemicals on plastic debris may be established globally, but the presence of a complex mixture of metals on plastic debris has only been recently demonstrated (Ashton et al. 2010; Holmes et al. 2012; Nakashima et al. 2011, 2012; Rochman et al. 2014a). Similar to organic chemicals, several metals have long been additive ingredients of plastics (e.g. lead added to PVC; Lithner et al. 2011; Nakashima et al. 2011, 2012), but now we have evidence that plastic debris accumulates metals from ocean water (Ashton et al. 2010; Holmes et al. 2012; Rochman et al. 2014a). Environmental accumulation of metals onto plastics may have been expected, as the surfaces of plastic containers are known 
to accumulate metals from water samples (Fischer et al. 2007; Weijuan et al. 2001; Robertson 1968). The accumulation of metals on marine plastic debris may be explained by both the chemical ingredients of the plastic (e.g. catalysts, fillers, plasticizers; Robertson 1968) and the degradation and fouling of aquatic plastic debris via microbial biofilms and colonization by algae and invertebrates (Holmes et al. 2012; Tien and Chen 2013) that may generate active sites for the sorption and/or bioaccumulation of metals. As such, similar to organic chemicals, plastic pellets may also serve as a passive sampler for metal contamination in the marine environment.

\subsubsection{Spatial Variability}

It should be noted that, similar to passive samplers, the types and concentrations of sorbed chemicals associated with marine plastic debris reflect the types and concentrations of chemical contaminants in ambient seawater. As such, the type and concentrations of chemicals sorbed to plastic debris will vary based upon the location that the debris is recovered on large (Ogata et al. 2009; Hirai et al. 2011; Fig. 5.2) and small spatial scales (Rochman et al. 2013c). Data from International Pellet Watch show that PCBs on plastic pellets collected from beaches spanning over $1000 \mathrm{~km}$ of the California coastline vary by one order of magnitude (23605 ng/g; www. pelletwatch.org). Similarly, pellets recovered from eight beaches throughout a single Californian county, San Diego (3.8-42 ng/g total PCBs; Van et al. 2011), and pellets deployed at different locations within a single bay, San Diego Bay (3.4-35 ng/g; Rochman et al. 2013c), had concentrations of PCBs that also varied by one order of magnitude. Moreover, variations in concentrations of metal contaminants recovered from four beaches along a stretch of coastline in Devon, England (Ashton et al. 2010) and deployed at several locations within the San Diego Bay, CA (Rochman et al. 2014a) varied similarly to organic contaminants, also by one order of magnitude. Thus, variability in contaminant burden

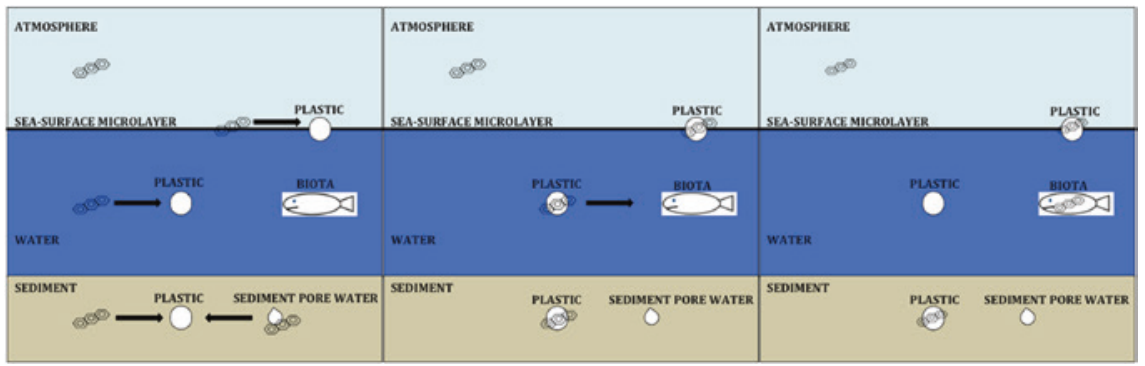

Fig. 5.2 Environmental fate diagram including plastic debris. The diagram represents how plastic debris may mediate the fate of some contaminants (e.g. PAHs) among different environmental compartments, including the sea-surface microlayer, water, sediment, sediment pore water and biota, in the marine environment 
reflects local sources and global chemical contamination. Such spatial variation has implications for the management, as discarded plastics may pose a greater hazard and thus a greater management priority in locations with greater point sources and greater concentrations of chemical pollutants.

\subsubsection{Variability by Plastic Type and Size}

Also of implication for management is how the accumulation of chemical contaminants may vary among type and size of plastic debris. If some plastic types tend to carry a smaller burden of contaminants due to their physical and chemical properties, items that often become marine debris (e.g. fishing and aquaculture gear; Andrady 2011) could be produced out of potentially safer plastic types.

There are several reasons why we might expect the behavior of contaminants to vary according to plastic type. The physical and chemical properties of each type of plastic [e.g. surface area (Teuten et al. 2007), diffusivity (Karapanagiot and Klontza 2008; Pascall et al. 2005; Rusina et al. 2007; Mato et al. 2001) and crystallinity (Karapanagioti and Klontza 2008; Mato et al. 2001)] influence the accumulation of chemicals to plastic debris (Pascall et al. 2005; Rusina et al. 2007) and accumulation patterns will be compound-specific (e.g. increasing in affinity to the polymer with greater hydrophobicity; Smedes et al. 2009). For organic chemicals, several studies show that polyethylene, polypropylene and polystyrene sorb greater concentrations of organic contaminants than PVC and polyethylene terephthalate (PET; Pascall et al. 2005; Teuten et al. 2007; Karapagioti and Klontza 2008; Rochman et al. 2013c, d). For some chemicals (i.e. PAHs), polyethylene and polystyrene sorb greater concentrations than polypropylene (Lee et al. 2014; Rochman et al. 2013c), whereas for others (i.e. PCBs) there is no detectable difference (Rochman et al. 2013c). Rubbery polymers, such as polyethylene and polypropylene are expected to demonstrate greater diffusion than the glassy polymers, PET and PVC, which may explain their greater sorptive capacity (Pascall et al. 2005). Polyethylene has a greater sorptive capacity than polypropylene (Teuten et al. 2007), probably due to its greater surface area (Teuten et al. 2007) and free volume (Pascall et al. 2005). Moreover, diffusion into the polymer has been observed in polyethylene pellets, but not in polypropylene (Karapanagioti and Klontza 2008). This is likely the reason that polyethylene has a large affinity for a wide range of organic contaminants varying in hydrophobicity (Müller et al. 2001) and is often used as a passive-sampling device (Lohmann 2012; Pascall et al. 2005). For polystyrene, the presence of benzene increases the distance between adjacent polymeric chains, which can make it easier for a chemical to diffuse into the polymer (Pascall et al. 2005), and may explain why contaminants sorb similarly to polystyrene as they do to polyethylene, despite being a glassy polymer (Pascall et al. 2005).

These trends may not extend to all classes of contaminants. Compound-specific interactions in the polymer phase are also important (Smedes et al. 2009). For example, PVC has a greater affinity for alkylbenzenes than does polyethylene 
(Wu et al. 2001). Moreover, for metal contaminants, there does not appear to be a large difference in sorption concentration among polymer types (Rochman et al. 2014a). A possible explanation is that the accumulation of metals to plastic may be immaterial, and the process may be mediated by a biofilm (Rochman et al. 2014a). In the aquatic environment, including marine systems, it is well established that biofilms have sorptive properties and accumulate metals and other contaminants (Decho 2000; Tien et al. 2009) and it has been suggested that the composition of biofilm does not vary significantly among plastic types (Ye and Andrady 1991; Zettler et al. 2013).

The sorption behavior of chemicals to plastic will also vary by size. Because of the difference in surface area, plastic of differing sizes will sorb contaminants accordingly (Koelmans et al. 2013; Velzeboer et al. 2014). Size will affect both the sorptive capacity and the rate at which chemicals are sorbed (Teuten et al. 2009). For example, nano- and micrometre-sized plastic debris may exchange organic chemicals faster than millimetre-sized plastic debris due to its larger surface area and short diffusion path lengths (Koelmans et al. 2013). Plastic may enter the ocean as nano- and micro-sized debris (e.g. as microscrubbers or laundry lint; Browne et al. 2011) or it may become smaller over time via photodegradation. Photodegradation of the polymer surface accelerates and increases the sorption capacity by altering surface properties and increasing surface area (Mato et al. 2001; Holmes et al. 2012; Rochman et al. 2013). The combination of increased sorption rate and capacity in smaller plastic debris may constitute increased risk in marine organisms (Velzeboer et al. 2014).

Thus, when assessing the hazard associated with plastic debris it is important to think holistically. Patterns are not simple or straightforward. While several lines of evidence show that polyethylene, polypropylene and polystyrene accumulate relatively large concentrations of some contaminants (e.g. POPs), polyethylene and polypropylene are made from the least hazardous monomers (Lithner et al. 2011) while polystyrene is made from the styrene monomer, which is a priority pollutant. Thus, the complex mixture of chemicals associated with plastic debris will be dependent on the type and size of the plastic and the location where it becomes marine debris.

\subsubsection{Plastic Debris, Environmental Chemical Contaminants and Environmental Fate}

The long-range transport, persistence and global dynamics of plastic debris are key aspects to understanding the ultimate fate of this material and any potential impacts of plastic debris on marine ecosystems. Because it is now globally accepted that plastic debris accumulates chemical contaminants (Ogata et al. 2009; Teuten et al. 2009), it is also important to understand how plastic debris mediates these same key aspects for environmental chemical contaminants. This then begs questions regarding: (1) how plastic debris fits into environmental fate models for 
chemical contaminant distribution and (2) how important plastic debris is relative to other media (e.g. water, sediment, biota) in driving processes of chemical distribution in the global oceans.

Chemical contaminants partition onto various environmental media, a process dependent upon the physical and chemical properties of each chemical and the physical and chemical properties of the environmental medium (e.g. sediment, water, organic matter, living biota). These processes, along with the chemical, physical and biological degradation of each chemical contaminant (Sinkonnen et al. 2000), help to determine their environmental fate globally. The addition of plastic to the marine environment adds a novel medium for chemical contaminants to interact with, and thus it is important to understand how plastic debris should be considered in future environmental fate models (Fig. 5.3). This section will discuss plastics as a novel environmental matrix and its potential role in helping to mediate the fate and distribution of chemical contaminants globally. Specifically, this section will discuss plastic debris as a sink and a source for chemical contaminants in the marine environment and how plastic may facilitate the global transport of chemicals in the marine environment and the transport of chemicals into marine foodwebs.

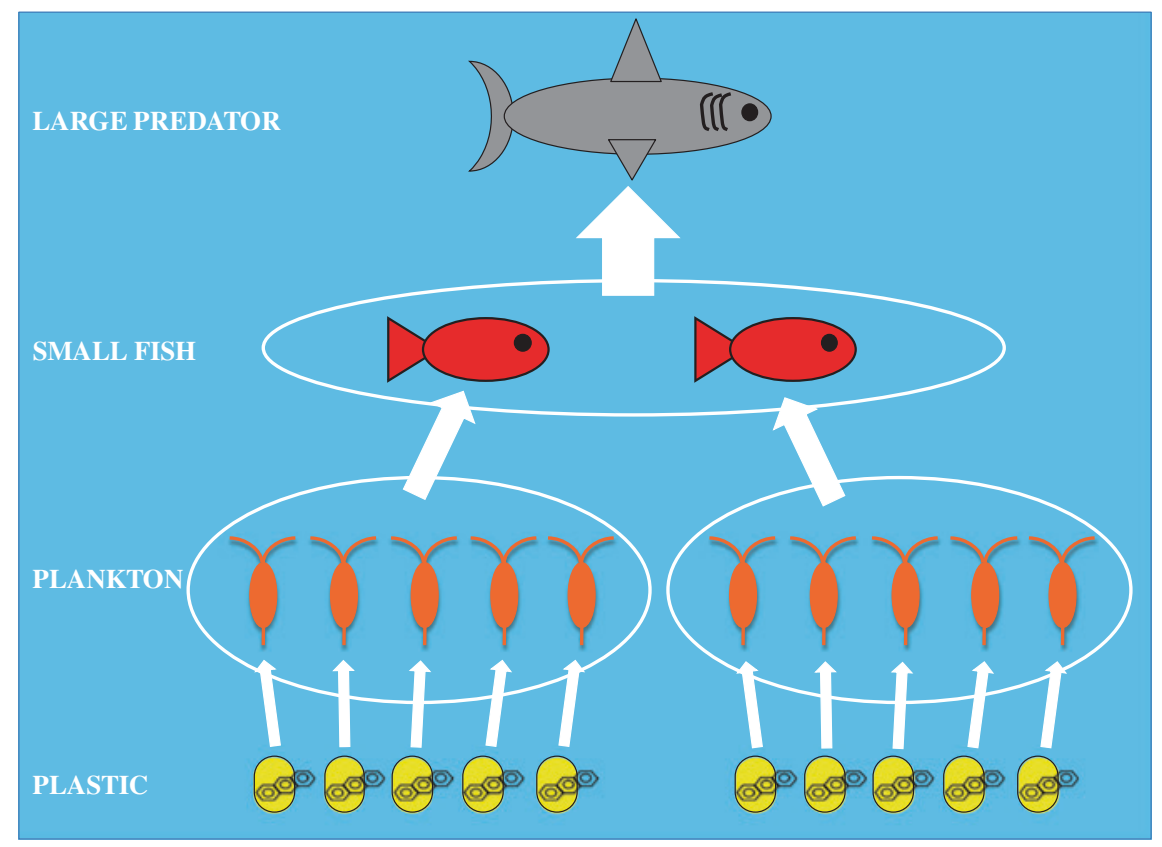

Fig. 5.3 Biomagnification of chemicals up the food chain. The diagram depicts a scenario whereby organic chemicals (e.g. PAHs) from plastic may transfer into lower trophic level organisms (e.g. zooplankton) via ingestion and accumulate at much greater concentrations via biomagnification in higher trophic level organisms (e.g. small fish and sharks), which may ultimately lead to contaminated seafood for humans as a result of plastic contamination in marine foodwebs. The size of the arrows depicts how the body burden (i.e. bioaccumulation of chemicals) may magnify in predators as compared to their prey 


\subsubsection{Plastic Debris as a Sink for Environmental Contaminants}

There is no doubt that plastic debris acts as a sink for chemical contaminants in the marine environment. What is less understood is the process by which this occurs, how this varies over space and time and by polymer and chemical, and how important plastic is as a sink for chemicals relative to other environmental media (e.g. sediment, water and biota). The primary focus of this section will be on processes of chemical accumulation, temporal trends and comparisons among other environmental media.

\subsubsection{Process of Accumulation}

As noted above, the concentration of chemicals that sorb to plastic debris varies according to polymer type and chemical substance. One reason for these differences is the mechanism by which chemicals accumulate on the plastic. For some plastics (i.e. polyethylene and polyoxymethylene), organic chemicals absorb into the polymeric matrix (providing greater surface area for chemicals to accumulate), whereas for other plastics the chemicals adsorb to the surface (Karapanagioti and Klontza 2008). As discussed above, these differences are related to the structure of each polymer type. Despite this, observations are not consistent among contaminant groups. As such, the polymer structure may be less important and instead accumulation may be primarily facilitated by other factors. In this case, it is important to note that changes that occur to the plastic when it becomes marine debris (e.g. fouling and degradation) can alter the structure of the plastic debris (e.g. increasing their surface area and/or charge; Artham et al. 2009; Holmes et al. 2012 , 2014), changing the way of how chemicals accumulate on the material.

\subsubsection{Rate of Accumulation}

Alterations of the plastic material when it becomes marine debris also impact the rate at which chemicals accumulate, also varying by polymer type and chemical of interest. For example, chemicals with less hydrophobicity and a lighter molecular weight reach saturation faster than those with greater hydrophobicity and a heavier molecular weight (Müller et al. 2001; Rochman et al. 2013c). Moreover, the mechanism by which chemicals accumulate will affect the rate of accumulation. For example, we observe faster saturation of POPs on PET and PVC whose glassy structure allow for adsorption only, than for polyethylene, where diffusion into the polymeric matrix facilitates a rapid adsorption to the surface followed by a slower increase via absorption (Rochman et al. 2013c).

Of concern for management is the slower rate of accumulation that occurs in the marine environment when compared to a laboratory setting. In a laboratory, 
chemicals (e.g. PAHs and metals) reach equilibrium on plastic in less than $72 \mathrm{~h}$ (Teuten et al. 2007; Holmes et al. 2012), whereas in the marine environment equilibrium occurs much slower (Mato et al. 2001; Rochman et al. 2013c). For example, on plastic pellets of various types (PET, PVC, polyethylene and polypropylene) that were deployed in a contaminated bay for up to 1 year, neither PCBs, PAHs or metals reached equilibrium for at least 3 months and in several cases did not reach equilibrium within the 1-year time period (Rochman et al. 2013c, 2014a). In the marine environment, the surface properties of the plastic debris consistently change. As plastic debris weathers it gains surface area, generates oxygen groups (increasing polarity; Mato et al. 2001; Fotopoulou and Karapanagioti 2012) and fouls (increasing their charge, roughness and porosity) (Artham et al. 2009) —all allowing plastic debris to accumulate increasingly larger concentrations of chemical contaminants (Holmes et al. 2012; Fotopoulou and Karapanagioti 2012; Rochman et al. 2013c, 2014a). Thus, in general, the longer the plastic is in the water, the greater concentrations of chemical contaminants it will accumulate (Engler et al. 2012), suggesting that plastic debris may become more hazardous the longer it remains at sea.

\subsubsection{Comparisons with Other Environmental Media}

Of greatest concern for management appears to be how the concentrations of hazardous chemicals accumulating on plastic debris compared to other environmental media. For several chemical groups it has been shown that pollutants can partition to plastic at greater than or equal concentrations than other environmental media. For example, POPs can accumulate on plastic debris at concentrations up to six orders of magnitude greater than ambient water (Ogata et al. 2009). Floating plastics are associated with the sea-surface microlayer, at the interface between the ocean and atmosphere, where large concentrations of chemical contaminants (e.g. PBTs and metals) accumulate due to its unique chemical composition (i.e. of lipids, fatty acids and proteins). Here, concentrations of organic contaminants are found at concentrations up to $500 \times$ greater than underlying waters (Wurl and Obbard 2004). As such, floating plastic debris could easily accumulate relatively large concentrations of chemical contaminants from this sea-surface microlayer (Mato et al. 2001), and may be one reason why we find large concentrations of chemicals on floating plastic debris recovered globally, including in remote regions (Heskett et al. 2012; Hirai et al. 2011). When comparing plastic debris to other solid matrices, concentrations of POPs on plastics have been found to accumulate at concentrations up to two orders of magnitude greater than on sediment and suspended particulates (Mato et al. 2001; Teuten et al. 2007) and concentrations of metals on plastics have been found at similar concentrations (Holmes et al. 2012) to those on nearby sediment. Still, a thermodynamically-based model, assuming equilibrium, predicts that with the current concentrations of plastic debris in the oceans the total fraction of POPs sorbed to plastic debris is negligible in relation to all other media globally (i.e. <1 \%; Gouin et al. 2011). 
The accumulation of chemicals on plastic debris has several potential implications for management. It could be positive if plastic debris aids in the removal of some chemicals from the environment. For example, they may act as a permanent sink when plastic debris transports vertically to the bottom of the ocean in the same way that sinking natural particles (e.g. phytoplankton cells and fecal pellets) are considered a final sink when they sequester POPs (Dachs et al. 2002). However, it may also be considered negative if it aids in the transport of hazardous chemicals to remote regions of the world and/or to marine food webs. As such, it is important to understand how plastic debris acts as a sink, and also as a source.

\subsubsection{Plastic Debris as a Source of Environmental Contaminants}

Plastic, like other PBTs (e.g. POPs; Sinkonnen et al. 2000; Dachs et al. 2002), are persistent and bioaccumulative, and thus can be transported long distances via ocean currents (Law et al. 2010; Maximenko et al. 2012) or by the migration of ocean life. As such, plastics debris may play a role in the transport of sorbed chemical contaminants and chemical ingredients globally (Engler et al. 2012; Cheng et al. 2013; Endo et al. 2013; Kwon et al. 2014).

\subsubsection{Global Transport}

While sorbed onto floating plastic debris, chemical contaminants may be transported long distances, including across or even to adjacent oceans (Zarfl and Matthies 2010; Engler et al. 2012). Negatively buoyant plastics, or plastic debris that becomes negatively buoyant upon fouling, will sink to the seafloor transporting any sorbed contaminants to the benthos where sediment-dwelling organisms reside. If these chemicals are released upon degradation of the material, plastic debris may be a source of chemical contaminants into pelagic and benthic marine habitats (Teuten et al. 2007; Hirai et al. 2011). While some contaminants may be lost due to biological or physical degradation (Sinkonnen et al. 2000; Rochman et al. 2013c), leaching of chemicals back to the environment may be of concern in remote and more pristine regions where sources of chemical contaminants are sparse (Teuten et al. 2007; Hirai et al. 2011; Heskett et al. 2012). Laboratory studies have found that plastics with sorbed POPs release a considerable amount of these chemicals upon being placed in clean water (Teuten et al. 2007; Endo et al. 2013).

The behavior of chemicals from plastic debris will likely be dependent upon location-specific considerations that include temperature, salinity, the intensity of solar radiation, biodegradation rates, and the presence of co-contaminants (Sinkonnen et al. 2000; Dachs et al. 2002; Bakir et al. 2012, 2014; Holmes et al. 2014). This process will also vary according to the hydrophobicity of the 
chemicals, such that chemicals with a greater hydrophobicity desorb much slower and may take years or even centuries to fully attain equilibrium (Endo et al. 2013). This has implications for management, as certain chemicals may transfer long distances holding onto the plastic as it migrates from a contaminated region to one that is remote and/or more pristine. Plastic debris sampled from remote regions with sporadic large concentrations of chemical support this theory (Hirai et al. 2011; Heskett et al. 2012).

A further consideration is how the transport of chemicals hitchhiking on plastic debris compares to other transport mechanisms, such as atmospheric or ocean currents. A group of researchers used thermodynamically-based model calculations (assuming sorptive equilibrium) to determine the relative importance of plastic debris as a source of PBTs to the remote Arctic Ocean (Zarfl and Matthies 2010). Their models conclude that transport via atmospheric and ocean currents are orders of magnitude larger than via plastic particles, determining that the contribution of PBTs from plastic debris may be negligible compared with annual PBT flux from other global-transport mechanisms (Zarfl and Matthies 2010). The authors warn that their model estimations include considerable uncertainty and suggest that future studies test the importance of plastic-mediated transport for chemicals with greater hydrophobicity and that are not generally transported via air or ocean currents (Zarfl and Matthies 2010). Moreover, there is a need to better understand the influence from different types of polymers and chemical contaminants (Gouin et al. 2011). The physical and chemical properties (e.g. boiling point, vapor pressure, water solubility and octanol-water partitioning) of the monomers and additive ingredients in addition to properties of the polymer (e.g. the size of the plastic and its pore size) are important when assessing the environmental fate of associated chemicals (Teuten et al. 2009; Lithner et al. 2011). For example, glassy polymers, like PVC, have a slower desorption rate than rubbery polymers, such as polyethylene (Teuten et al. 2009). Moreover, one should consider how desorption may differ in the presence of the microbial biofouling that populates plastic debris in the marine environment (Zettler et al. 2013) and may provide greater surface area for sorption, biodegrade and/or transform the chemical contaminants, or facilitate chemical leaching or transport into other environmental media, including the biota (Gouin et al. 2011).

\subsubsection{Food Web Transport}

Several researchers have tried to understand the role of plastic debris as a source of chemical contaminants into the foodweb, raising several questions regarding: (i) whether contaminants transfer from the plastic to animals upon ingestion, (ii) how important this may be relative to other sources of contaminants in foodwebs and (iii) if contaminants from plastic debris biomagnify in top predators. These questions have been explored using computer modeling (Teuten et al. 2007; Gouin et al. 2011; Koelmans et al. 2013, 2014; Koelmans 2015), assessing correlations between plastic ingestion and chemical body burdens (Ryan et al. 1988; 
Teuten et al. 2009; Yamashita et al. 2011; Tanaka et al. 2013; Lavers et al. 2014) and/or using experimental techniques to measure the bioaccumulation of chemicals from plastic in laboratory animals (Gaylor et al. 2012; Besseling et al. 2013; Browne et al. 2013; Rochman et al. 2013b; Chua et al. 2014). Modeling approaches are useful for interpreting experimental and observation data, as well as for risk assessment of the hazards caused by plastic ingestion in wildlife (Koelmans 2015). Because this is discussed in detail by Koelmans (2015), the discussion here will be limited to observational data in the field and experimental data in the laboratory.

There are several lines of evidence suggesting that chemical contaminants do transfer from plastic debris to marine animals. Correlative evidence in the field and laboratory shows that the concentrations of PCBs (Ryan et al. 1988; Teuten et al. 2009; Yamashita et al. 2011) and trace metals (Lavers et al. 2014) in seabirds are positively correlated with the mass of ingested plastic. Moreover, seabirds collected from the North Pacific were found with similar congener patterns of PBDEs in their tissues as those found on the ingested plastic in their gut content (Tanaka et al. 2013) and myctophid fish collected from the South Atlantic were found with similar congener patterns of PBDEs in their tissues as those found on the plastic debris in the region (Rochman et al. 2014b). These observational data suggest that plastic-associated chemicals from plastic do transfer to wildlife upon ingestion.

This hypothesis has been further investigated in controlled laboratory studies, providing a stronger weight of evidence. Two studies demonstrated the bioaccumulation of additive PBDEs in crickets (Acheta domesticus; Gaylor et al. 2012) and amphipods (Allorchestes compressa; Chua et al. 2014) as a result of the ingestion of plastic. Another study showed greater concentrations of PCBs in lugworms exposed to contaminated sediment with polystyrene as opposed to contaminated sediment without plastic, suggesting that the existence of the plastic in the experiment facilitated the transfer of chemicals to lugworms (Arenicola marina; Besseling et al. 2013). Another laboratory study demonstrated that both additive chemicals and chemicals that accumulate in nature (nonylphenol, phenanthrene, PBDE-47 and triclosan) desorb from PVC and can transfer into the tissues of lugworms upon ingestion (A. marina; Browne et al. 2013). Lastly, a study measuring the bioaccumulation of POPs sorbed to plastics demonstrated the transfer of chrysene, PCB 28 and several congeners of PBDEs to fish from the ingestion of polyethylene pellets (Rochman et al. 2013b). Thus, there is strong evidence showing that chemical contaminants can bioaccumulate in marine life when plastic debris is ingested. What remains less understood, is whether these plastic-associated contaminants biomagnify in higher trophic level animals as a direct result of plastic ingestion (potentially leading to bioaccumulation of plastic-derived chemicals in seafood; Fig. 5.3) and how important bioaccumulation from plastic is relative to bioaccumulation from other sources of chemical contamination in the environment (e.g. chemical contamination that is ubiquitous in water, sediments and food webs globally; Ross and Birnbaum 2010). Still, the fact that chemicals from plastic debris can transfer to marine animals begs the question, how do these chemicals associated with plastic debris impact marine organisms? 


\subsection{Toxicity of Plastic Debris to Marine Life}

Hazardous substances may be emitted during all phases of the life cycle of a plastic product (Lithner et al. 2011; Galloway 2015). When the ultimate fate of a plastic product is the marine environment, plastic debris carries a cocktail of contaminants, including those that accumulate on the material from the ocean water. If these chemicals become bioavailable, they can penetrate cells and chemically interact with biologically important molecules, and may cause adverse effects including changes in behavior (Browne et al. 2013), liver toxicity (Rochman et al. 2013b) and endocrine disruption (Teuten et al. 2009; Rochman et al. 2014c). This section will discuss what is currently understood regarding the potential for chemicals associated with marine plastic debris to impact marine organisms.

\subsubsection{Hazards Associated with Plastic Ingredients}

Several of the ingredients associated with plastics are considered hazardous by regulatory agencies (Lithner et al. 2011; Rochman 2013; Browne et al. 2013; USEPA 2013; European Commision 2014). Polymerization reactions are rarely complete and unpolymerized residual monomers can migrate off the plastic (Lithner et al. 2011). Moreover, additive ingredients are not usually bound to the polymer matrix, and often account for the major leaching and emissions of chemical substances from plastic materials (Lithner et al. 2011; Engler et al. 2012). Release of hazardous substances, including phthalates, brominated flame retardants, bisphenol A, formaldehyde, acetaldehyde, 4-nonylphenol and many volatile organic compounds, from plastic products has been shown (Crain et al. 2007; Lithner et al. 2012). As such, these chemicals may be bioavailable to marine life and thus there is potential for organisms to be impacted by the chemical ingredients associated with plastic debris.

For some plastics, the monomer that makes up the polymer itself is classified as hazardous. For example, polyurethane foam, PVC, polycarbonate and high-impact polystyrene, are composed of monomers that are considered carcinogenic, mutagenic or toxic for reproduction (Lithner et al. 2011). Other monomers that have been described as the most environmentally hazardous are $\mathrm{m}$-phenylenediamine, p-phenylenediamine, 1,4-dichlorobenzene and the phthalate plasticizer BBP (used as a monomer in some PVC), all of which have been found to be acutely toxic to aquatic life (Lithner et al. 2011).

Several plastics are composed of monomers considered to be non-hazardous (e.g. polyethylene and polypropylene), but contain harmful additives. Some of the most hazardous additives include brominated flame retardants, polyfluoronated compounds, triclosan, phthalate plasticizers and lead heat stabilizers (Halden et al. 2010; Lithner et al. 2011). Phthalates, for example, have been shown to target nuclear hormone receptor signaling pathways (Grün and Blumberg 2007) and cause endocrine disrupting effects in fish (Kim et al. 2002). Adverse effects 
related to the brominated flame-retardants include neurobehavioral development disorders, thyroid hormone alterations, teratogenicity and reduction in spawning success (Darnerud 2003; de Wit 2002). Other additives have hazardous degradation products. For example, nonylphenol is a degradation product of nonylphenol ethoxylates, a surfactant, and can cause endocrine disruption in fish (Gray and Metcalfe 1997; Seki et al. 2003; Kawahata et al. 2004).

When trying to understand how plastic debris may impact ocean organisms, it is critical to measure effects at environmentally relevant concentrations and under environmentally relevant exposure conditions (Rochman and Boxall 2014). While some evidence of toxicity for these substances occurs at levels greater than those found in the environment, for several chemical ingredients (e.g. phthalates and bisphenol A) adverse effects have been demonstrated at environmentally relevant concentrations (Crain et al. 2007; Oehlmann et al. 2009). Moreover, organisms are rarely exposed to one chemical in isolation, and the interaction of several chemicals may induce synergistic effects. As such, when considering the impacts to organisms from plastic debris one must consider the complex mixture of chemicals associated with this material in the marine environment.

\subsubsection{Hazards Associated with the Complex Mixture of Plastic and Sorbed Pollutants}

Here, we will not focus on any physical adverse effects from the material itself, although it is worth noting that plastic debris may act as a multiple stressor to marine organisms as a result of the combination of both physical and chemical stressors (Rochman 2013). In this chapter, we will discuss the existing evidence of adverse chemical effects from the complex mixture of chemicals associated with plastic products and plastic marine debris. See Kühn et al. (2015) and Lusher (2015) for information regarding any adverse effects from plastic debris not related to the chemical impacts.

Some studies have assessed the toxicity of the leachates from plastic products. These incorporate adverse effects from the complex mixture of chemical ingredients associated with the material. One researcher exposed Daphnia magna to leachates from several plastic products and found that all leachates from PVC, polyurethane and epoxy products were acutely toxic (48-h EC50 s) at concentrations ranging from 2 to 235 grams of plastic per liter of water (Lithner et al. 2009, 2012). Another study found that most of the 500 plastic products sampled leached chemicals that had estrogenic activity, detected by an E-screen assay (Yang et al. 2011). Similarly, Wagner and Oehlmann (2009, 2011) detected estrogenic contamination in PET water bottles, concluding that PET packaging materials are a source of estrogen-like compounds.

Moreover, when plastic becomes marine debris, it accumulates several other priority pollutants from the surrounding seawater, including several organic pollutants and metals. Ecotoxicological work has shown that priority pollutants such 
as these can degrade the structure and functions of ecosystems. Key physiological processes of organisms (e.g. cell-division, immunity, secretion of hormones) can be disrupted, causing disease (e.g. cancer; Zhuang et al. 2009; Vasseur and Cossu-Leguille 2006; Oehlmann et al. 2009) and reducing the ability to escape predators (Cartwright et al. 2006) and reproduce (Brown et al. 2004). Recently, some evidence has emerged regarding the impacts associated with the complex mixture of plastic and sorbed contaminants to organisms. One laboratory study found that the ingestion of PVC with sorbed triclosan altered feeding behavior and caused mortality in lugworms (A. marina; Browne et al. 2013). Another study fed fish polyethylene that had been deployed in the San Diego Bay, CA (i.e. allowing the plastic to accumulate environmentally relevant concentrations of priority pollutants). After a two-month dietary exposure to plastic with a complex mixture of sorbed priority pollutants (POPs and metals), fish suffered from liver toxicity, including glycogen depletion, lipidosis, cellular death and tumor promotion (Rochman et al. 2013b) and showed signs of endocrine disruption via changes in gene expression and abnormal growth of germ cells in the gonads (Rochman et al. 2014c). In both studies, adverse effects were demonstrated from the plastic alone, but organisms suffered greater effects when exposed to the mixture of plastic with sorbed chemical contaminants (Browne et al. 2013; Rochman et al. 2013b), further supporting the idea that when assessing the hazards of plastic debris it is important to consider the complex mixture of plastic debris, chemical ingredients and any sorbed chemical contaminants.

\subsection{Conclusion}

There are many different plastic polymers and several thousand plastic additives. The combination of these makes a large variation in chemical composition of plastic products. The unique combination of chemical ingredients may render some types of plastic more hazardous than others when their chemical constituents are bioavailable to organisms. Moreover, the chemical properties of plastic facilitate the accumulation of relatively large concentrations of contaminants, producing a complex mixture of chemical contaminants on marine plastic debris. The mixture and concentrations of hazardous chemicals will vary based upon the plastic type, the location where the material is discarded and the time it is left in the aquatic environment. Research has shown that marine plastic debris may act as both a sink and a source for contaminants in the marine environment, including their transfer into marine foodwebs, and thus need to be considered in models assessing the environmental fate of contaminants in the ocean. Moreover, this complex mixture of contaminants associated with marine plastic debris should be considered under risk assessment for marine animals exposed to this debris. Assessing such hazards associated with plastic in aquatic habitats is not simple, and requires knowledge regarding organisms that may be exposed, the exposure concentrations, the types of polymers comprising the debris, the length of time the debris was present in the 
aquatic environment (affecting the size, shape and fouling) and the locations and transport of the debris during that time period.

Although the scientific understanding regarding the fate and consequences of this material in the environment is growing, there remain several gaps in our understanding regarding the cocktail of chemicals associated with marine plastic debris. To design effective management strategies for mitigating any impacts, policy-makers will benefit from a greater understanding regarding the importance of plastic debris as a sink and source for global contaminants, its role in the global transport of chemicals substances, the bioaccumulation of plastic ingredients and accumulated chemical contaminants in wildlife, the importance of plastic as a mechanism for foodweb contamination relative to other sources of priority pollutants and whether or not these chemicals biomagnify in top predators (including humans) as a consequence of plastic debris entering marine foodwebs. Today, while researchers continue to expand our knowledge base, policy-makers can begin to act with the current information available, as there are no signs that the amount of plastic debris entering the marine environment is decreasing (Law et al. 2010; Goldstein et al. 2012) and if we continue business-as-usual the planet will hold another 33 billion tons of plastic by the year 2050 (Rochman 2013; Browne et al. 2013).

Open Access This chapter is distributed under the terms of the Creative Commons Attribution Noncommercial License, which permits any noncommercial use, distribution, and reproduction in any medium, provided the original author(s) and source are credited.

\section{References}

Artham, T., Sudhakar, M., Venkatesan, R., Madhavan Nair, C., Murty, K. V. G. K., \& Doble, M. (2009). Biofouling and stability of synthetic polymers in sea water. International Biodeterioration and Biodegradation, 63(7), 884-890.

Anderson, B. S., Middaugh, D. P., Hunt, J. W., \& Turpen, S. L. (1991). Copper toxicity to sperm, embryos and larvae of topsmelt Atherinops affinis, with notes on induced spawning. Marine Environmental Research, 31(1), 17-35.

Andrady, A. L. (2011). Microplastics in the marine environment. Marine Pollution Bulletin, 62(8), 1596-1605.

Antunes, J. C., Frias, J. G. L., Micaelo, A. C., \& Sobral, P. (2013). Resin pellets from beaches of the Portuguese coast and adsorbed persistent organic pollutants. Estuarine Coastal and Shelf Science, 130, 62-69.

Ashton, K., Holmes, L., \& Turner, A. (2010). Association of metals with plastic production pellets in the marine environment. Marine Pollution Bulletin, 60, 2050-2055.

Bakir, A., Rowland, S. J., \& Thompson, R. C. (2012). Competitive sorption of persistent organic pollutants onto microplastics in the marine environment. Marine Pollution Bulletin, 64, 2782-2789.

Bakir, A., Rowland, S. J., \& Thompson, R. C. (2014). Transport of persistent organic pollutants by microplastics in estuarine conditions. Estuarine Coastal and Shelf Science, 140, 14-21.

Barnes, D. K., Galgani, F., Thompson, R. C., \& Barlaz, M. (2009). Accumulation and fragmentation of plastic debris in global environments. Philosophical Transactions of the Royal Society B, 364(1526), 1985-1998. 
Bauer, M. J., \& Herrmann, R. (1997). Estimation of the environmental contamination by phthalic acid esters leaching from household wastes. Science of the Total Environment, 208, 49-57.

Besseling, E., Wegner, A., Foekema, E., Van Den Heuvel-Greve, M., \& Koelmans, A. A. (2013). Effects of microplastic on fitness and PCB bioaccumulation by the lugworm Arenicola marina (L.). Environmental Science and Technology, 47, 593-600.

Binetti, R., Costamagna, F. M., \& Marcello, I. (2008). Exponential growth of new chemicals and evolution of information relevant to risk control. Annali dell'Istituto Superiore di Sanita, 44, 13-15.

Braun, D., Cherdron, H., Rehahn, M., Ritter, H., \& Voit, B. (2005). Polymer synthesis: Theory and practice - fundamentals, methods, experiments (4th ed.). Berlin: Springer.

Brown, R. J., Galloway, T. S., Lowe, D., Browne, M. A., Dissanayake, A., et al. (2004). Differential sensitivity of three marine invertebrates to copper assessed using multiple biomarkers. Aquatic Toxicology, 66, 267-278.

Browne, M. A., Crump, P., Niven, S. J., Teuten, E. L., Tonkin, A., Galloway, T., et al. (2011). Accumulations of microplastic on shorelines worldwide: Sources and sinks. Environmental Science and Technology, 45, 9175-9179.

Browne, M. A., Niven, S. J., Galloway, T. S., Rowland, S. J., \& Thompson, R. C. (2013). Microplastic moves pollutants and additives to worms, reducing functions linked to health and biodiversity. Current Biology, 23(23), 2388-2392.

Carpenter, E., \& Smith, K. (1972). Plastics on the Sargasso Sea surface. Science, 175, 1240-1241.

Cartwright, S. R., Coleman, R. A., \& Browne, M. A. (2006). Ecologically relevant effects of pulse application of copper on the limpet. Patella vulgata. Marine Ecology Progress Series, 326, 187-194.

Cheng, W., Xie, Z., Blais, J. M., Zhang, P., Li, M., Yang, C., et al. (2013). Organophosphorus esters in the oceans and possible relation with ocean gyres. Environmental Pollution, 180, 159-164.

Chua, E., Shimeta, J., Nugegoda, D., Morrison, P. D., \& Clarke, B. O. (2014). Assimilation of Polybrominated diphenyl ethers from microplastics by the marine amphipod, Allorchestes compressa. Environmental Science and Technology, 48(14), 8127-8134.

Crain, D. A., Eriksen, M., Iguchi, T., Jobling, S., Laufer, H., LeBlanc, G. A., et al. (2007). An ecological assessment of bisphenol-A: Evidence from comparative biology. Reproductive Toxicology, 24(2), 225-239.

Dachs, J., Lohmann, R., Ockenden, W. A., Méjanelle, L., Eisenreich, S. J., \& Jones, K. C. (2002). Oceanic biogeochemical controls on global dynamics of persistent organic pollutants. Environmental Science and Technology, 36(20), 4229-4237.

Darnerud, P. O. (2003). Toxic effects of brominated flame retardants in man and in wildlife. Environment International, 29(6), 841-853.

Decho, A. W. (2000). Microbial biofilms in intertidal systems: An overview. Continental Shelf Research, 20, 1257-1273.

Desforges, J. P. W., Galbraith, M., Dangerfield, N., \& Ross, P. S. (2014). Widespread distribution of microplastics in subsurface seawater in the NE Pacific Ocean. Marine Pollution Bulletin, 79(1), 94-99.

de Wit, C. A. (2002). An overview of brominated flame retardants in the environment. Chemosphere, 46(5), 583-624.

Endo, S., Takizawa, R., Okuda, K., Takada, H., Chiba, K., et al. (2005). Concentration of polychlorinated biphenyls (PCBs) in beached resin pellets: Variability among individual particles and regional differences. Marine Pollution Bulletin, 50(10), 1103-1114.

Endo, S., Yuyama, M., Takada, H. (2013). Desorption kinetics of hydrophobic organic contaminants from marine plastic pellets. Marine Pollution Bulletin, 74(1), 125-131.

Engler, R. E. (2012). The complex interaction between marine debris and toxic chemicals in the ocean. Environmental Science and Technology, 46(22), 12302-12315.

Eriksen, M., Lebreton, L. C. M., Carson, H. S., Thiel, M., Moore, C. J., Borerro, J. C., et al. (2014). Plastic pollution in the world's oceans: More than 5 trillion plastic pieces weighing over 250,000 tons afloat at sea. PLoS ONE, 9, e111913.

European Commission. (2014). Priority substances and certain other pollutants according to Annex II of directive 2008/105/EC. http://ec.europa.eu/environment/water/water-framework/ priority_substances.htm. 
Fischer, A. C., Kroon, J. J., Verburg, T. G., Teunissen, T., \& Wolterbeer, H. T. (2007). On the relevance of iron adsorption to container materials in small-volume experiments on iron marine chemistry: ${ }^{55} \mathrm{Fe}$-aided assessment of capacity, affinity and kinetics. Marine Chemistry, 107, 533-546.

Fisner, M., Taniguchi, S., Moreira, F., Bícego, M. C., \& Turra, A. (2013). Polycyclic aromatic hydrocarbons (PAHs) in plastic pellets: Variability in the concentration and composition at different sediment depths in a sandy beach. Marine Pollution Bulletin, 70, 219-226.

Fossi, M. C., Panti, C., Guerranti, C., Coppola, D., Giannetti, M., Marsili, L., et al. (2012). Are baleen whales exposed to the threat of microplastics? A case study of the Mediterranean fin whale (Balaenoptera physalus). Marine Pollution Bulletin, 64(11), 2374-2379.

Fossi, M. C., Coppola, D., Baini, M., Giannetti, M., Guerranti, C., Marsili, L., et al. (2014). Large filter feeding marine organisms as indicators of microplastic in the pelagic environment: The case studies of the Mediterranean basking shark (Cetorhinus maximus) and fin whale (Balaenoptera physalus). Marine Environmental Research 100, 17-24.

Fotopoulou, K. N., \& Karapanagioti, H. K. (2012). Surface properties of beached plastic pellets. Marine Environmental Research, 81, 70-77.

Fries, E., \& Zarfl, C. (2012). Sorption of polycyclic aromatic hydrocarbons (PAHs) to low and high density polyethylene (PE). Environmental Science and Pollution Research, 19(4), 1296-1304.

Galgani, F., Leaute, J. P., Moguedet, P., Souplet, A., Verin, Y., Carpentier, A. et al. (2000). Litter on the sea floor along European coasts. Marine Pollution Bulletin, 40(6), 516-527.

Galloway, T. S. (2015). Micro- and nano-plastics and human health. In M. Bergmann, L. Gutow \& M. Klages (Eds.), Marine anthropogenic litter (pp. 347-370). Berlin: Springer.

Gaylor, M. O., Harvey, E., \& Hale, R. C. (2012). House crickets can accumulate polybrominated diphenyl ethers (PBDEs) directly from polyurethane foam common in consumer products. Chemosphere, 86(5), 500-505.

Goldberg, E. D. (1997). Plasticizing the seafloor: an overview. Environmental Technology, 18(2), 195-201.

Goldstein, M. C., Rosenberg, M., \& Cheng, L. (2012). Increased oceanic microplastic debris enhances oviposition in an endemic pelagic insect. Biology Letters, 8(5), 817-820.

Goldstein, M. C., Titmus, A. J., \& Ford, M. (2013). Scales of spatial heterogeneity of plastic marine debris in the northeast Pacific ocean. PLoS One, 8(11), e80020.

Gouin, T., Roche, N., Lohmann, R., \& Hodges, G. (2011). A thermodynamic approach for assessing the environmental exposure of chemicals absorbed to microplastic. Environmental Science and Technology, 45(4), 1466-1472.

Gowariker, V. R., Viswanathan, N. V., \& Sreedhar, J. (2003). Polymer science. New Dehli: New Age International.

Gray, M. A., \& Metcalfe, C. D. (1997). Induction of testis-ova in Japanese medaka (Oryzias latipes) exposed to p-nonylphenol. Environmental Toxicology and Chemistry, 16(5), 1082-1086.

Grün, F., \& Blumberg, B. (2007). Perturbed nuclear receptor signaling by environmental obesogens as emerging factors in the obesity crisis. Reviews in Endocrine and Metabolic Disorders, 8(2), 161-171.

Halden, R. U. (2010). Plastics and health risks. Annual Review of Public Health, 31, 179-194.

Heskett, M., Takada, H., Yamashita, R., Yuyama, M., Ito, M., et al. (2012). Measurement of persistent organic pollutants (POPs) in plastic resin pellets from remote islands: Toward establishment of background concentrations for International Pellet Watch. Marine Pollution Bulletin, 64, 445-448.

Hidalgo-Ruz, V., \& Thiel, M. (2015). The contribution of citizen scientists to the monitoring of marine litter. In M. Bergmann, L. Gutow, M. Klages (Eds.), Marine anthropogenic litter (pp. 433-451). Berlin: Springer.

Hirai, H., Takada, H., Ogata, Y., Yamashita, R., Mizukawa, K., et al. (2011). Organic micropollutants in marine plastic debris from the open ocean and remote and urban beaches. Marine Pollution Bulletin, 62, 1683-1692.

Holmes, L. A., Turner, A., \& Thompson, R. C. (2012). Adsorption of trace metals to plastic resin pellets in the marine environment. Environmental Pollution, 160, 42-48. 
Holmes, L. A., Turner, A., \& Thompson, R. C. (2014). Interactions between trace metals and plastic production pellets under estuarine conditions. Marine Chemistry, 167, 25-32.

Huckins, J., Manuweera, G., Petty, J., Mackay, D., \& Lebo, J. (1993). Lipid-containing semipermeable membrane devices for monitoring organic contaminants in water. Environmental Science and Technology, 27, 2489-2496.

Karapanagioti, H. K., \& Klontza, I. (2008). Testing phenanthrene distribution properties of virgin plastic pellets and plastic eroded pellets found on Lesvos island beaches (Greece). Marine Environmental Research, 65, 283-290.

Kawahata, H., Ohta, H., Inoue, M., \& Suzuki, A. (2004). Endocrine disrupter nonylphenol and bisphenol A contamination in Okinawa and Ishigaki Islands, Japan-within coral reefs and adjacent river mouths. Chemosphere, 55(11), 1519-1527.

Kim, E. J., Kim, J. W., \& Lee, S. K. (2002). Inhibition of oocyte development in Japanese medaka (Oryzias latipes) exposed to di-2-ethylhexyl phthalate. Environment International, 28(5), 359-365.

Koelmans, A. A. (2015). Modeling the role of microplastics in bioaccumulation of organic chemicals to marine aquatic organisms. Critical review. In M. Bergmann, L. Gutow \& M. Klages (Eds.), Marine anthropogenic litter (pp. 313-328). Berlin: Springer.

Koelmans, A. A., Besseling, E., Wegner, A., \& Foekema, E. M. (2013). Plastic as a carrier of POPs to aquatic organisms: A model analysis. Environmental Science and Technology, 47, $7812-7820$.

Koelmans, A. A., Besseling, E., \& Foekema, E. M. (2014). Leaching of plastic additives to marine organisms. Environmental Pollution, 187, 49-54.

Kühn, S., Bravo Rebolledo, E. L., \& van Franeker, J. A. (2015). Deleterious effects of litter on marine life. In M. Bergmann, L. Gutow \& M. Klages (Eds.), Marine anthropogenic litter (pp. 75-116). Berlin: Springer.

Kwon, E., \& Castaldi, M. J. (2008). Investigation of mechanisms of polycyclic aromatic hydrocarbons (PAHs) initiated from the thermal degradation of styrene butadiene rubber (SBR) in $\mathrm{N}_{2}$ atmosphere. Environmental Science and Technology, 42, 2175-2180.

Kwon, B. G., Saido, K., Koizumi, K., Sato, H., Ogawa, N., Chung, S. Y., et al. (2014). Regional distribution of styrene analogues generated from polystyrene degradation along the coastlines of the North-East Pacific Ocean and Hawaii. Environmental Pollution, 188, 45-49.

Laist, D. W. (1987). Overview of the biological effects of lost and discarded plastic debris in the marine environment. Marine Pollution Bulletin, 18(6), 319-326.

Lavers, J. L., Bond, A. L., \& Hutton, I. (2014). Plastic ingestion by flesh-footed Shearwaters (Puffinus carneipes): Implications for fledgling body condition and the accumulation of plastic-derived chemicals. Environmental Pollution, 187, 124-129.

Law, K. L., Morét-Ferguson, S., Maximenko, N. A., Proskurowski, G., Peacock, E. E., et al. (2010). Plastic accumulation in the North Atlantic subtropical gyre. Science, 329(5996), 1185-1188.

Law, K. L., Morét-Ferguson, S. E., Goodwin, D. S., Zettler, E. R., DeForce, E., Kukulka, T., er al. (2014). Distribution of surface plastic debris in the Eastern Pacific Ocean from an 11-year data set. Environmental Science and Technology, 48(9), 4732-4738.

Lee, H., Shim, W. J., \& Kwon, J. H. (2014). Sorption capacity of plastic debris for hydrophobic organic chemicals. Science of the Total Environment, 470, 1545-1552.

Lithner, D., Damberg, J., Dave, G., \& Larsson, Å. (2009). Leachates from plastic consumer products-screening for toxicity with Daphnia magna. Chemosphere, 74(9), 1195-1200.

Lithner, D., Larsson, A., \& Dave, G. (2011). Environmental and health hazard ranking and assessment of plastic polymers based on chemical composition. Science of the Total Environment, 409, 3309-3324.

Lithner, D., Nordensvan, I., \& Dave, G. (2012). Comparative acute toxicity of leachates from plastic products made of polypropylene, polyethylene, PVC, acrylonitrile-butadiene-styrene, and epoxy to Daphnia magna. Environmental Science and Pollution Research, 19(5), 1763-1772.

Lohmann, R. (2012). Critical review of low-density polyethylene's partitioning and diffusion coefficients for trace organic contaminants and implications for its use as a passive sampler. Environmental Science and Technology, 46, 606-618. 
Lusher, A. (2015). Microplastics in the marine environment: Distribution, interactions and effects. In M. Bergmann, L. Gutow \& M. Klages (Eds.), Marine anthropogenic litter (pp. 245-308). Berlin: Springer.

Lynge, E., Anttila, A., \& Hemminki, K. (1997). Organic solvents and cancer. Cancer Causes and Control, 8(3), 406-419.

Mato, Y., et al. (2001). Plastic resin pellets as a transport medium for toxic chemicals in the marine environment. Environmental Science and Technology, 35, 318-324.

Maximenko, N., Hafner, J., \& Niiler, P. (2012). Pathways of marine debris derived from trajectories of Lagrangian drifters. Marine Pollution Bulletin, 65(1), 51-62.

Müller, J. F., Manomanii, K., Mortimer, M. R., \& McLachlan, M. S. (2001). Partitioning of polycyclic aromatic hydrocarbons in the polyethylene/water system. Fresenius Journal of Analytical Chemistry, 371, 816-822.

Nakashima, E., Isobe, A., Magome, S., Kako, S. I., \& Deki, N. (2011). Using aerial photography and in situ measurements to estimate the quantity of macro-litter on beaches. Marine Pollution Bulletin, 62(4), 762-769.

Nakashima, E., Isobe, A., Kako, S. I., Itai, T., \& Takahashi, S. (2012). Quantification of toxic metals derived from macroplastic litter on Ookushi Beach, Japan. Environmental Science and Technology, 46(18), 10099-10105.

OECD. (2004). Emission scenario document on plastic additives. Series on emission scenario documents, no. 3. Paris: Environmental Directorate, OECD Environmental Health and Safety Publications.

Oehlmann, J., Fioroni, P., Stroben, E., \& Markert, B. (1996). Tributyltin (TBT) effects on Ocinebrina aciculate (Gastropoda: Muricidae): Imposex development, sterilization, sex change and population decline. Science of the Total Environment, 188(2), 205-223.

Oehlmann, J., Schulte-Oehlmann, U., Kloas, W., Jagnytsch, O., Lutz, I., et al. (2009). A critical analysis of the biological impacts of plasticizers on wildlife. Philosophical Transactions of the Royal Society B, 364(1526), 2047-2062.

Ogata, Y., Takada, H., Mizukawa, K., Hirai, H., Iwasa, S., Endo, S., et al. (2009). International pellet watch: Global monitoring of persistent organic pollutants (POPs) in coastal waters. 1. Initial phase data on PCBs, DDTs, and HCHs. Marine Pollution Bulletin, 58, 1437-1446.

Papaleo, B., Caporossi, L., Bernardini, F., Cristadoro, L., Bastianini, L., De Rosa, M., et al. (2011). Exposure to styrene in fiberglass-reinforced plastic manufacture: Still a problem. Journal of Occupational and Environmental Medicine, 53(11), 1273-1278.

Pascall, M. A., Zabik, M. E., Zabik, M. J., \& Hernandez, R. J. (2005). Uptake of Polychlorinated biphenyls (PCBs) from an aqueous medium by polyethylene, polyvinyl chloride, and polystyrene films. Journal of Agricultural and Food Chemistry, 53, 164-169.

PlasticsEurope, Plastics - the facts 2013: An analysis of European plastics production, demand and waste data. http://www.plasticseurope.org/Document/plastics-the-facts-2013.aspx?FolID=2.

Rios, L. M., Moore, C., \& Jones, P. R. (2007). Persistent organic pollutants carried by synthetic polymers in the ocean environment. Marine Pollution Bulletin, 54(8), 1230-1237.

Rios, L. M., Jones, P. R., Moore, C., \& Narayan, U. V. (2010). Quantitation of persistent organic pollutants adsorbed on plastic debris from the Northern Pacific Gyre's "eastern garbage patch". Journal of Environmental Monitoring, 12(12), 2226-2236.

Robertson, D. E. (1968). The adsorption of trace chemicals in sea water on various container surfaces. Analytica Chimica Acta, 42, 533-536.

Rochman, C. M. (2013). Plastics and priority pollutants: A multiple stressor in aquatic habitats. Environmental Science and Technology, 47, 2439-2440.

Rochman, C. M., Browne, M. A., Halpern, B. S., Hentschel, B. T., Hoh, E., Karapanagioti, H., et al. (2013a). Classify plastic waste as hazardous. Nature, 494, 169-171.

Rochman, C. M., Hoh, E., Kurobe, T., \& Teh, S. J. (2013b). Ingested plastic transfers hazardous chemicals to fish and induces hepatic stress. Scientific Reports, 3, 3263.

Rochman, C. M., Hoh, E., Hentschel, B. T., \& Kaye, S. (2013c). Long-term field measurement of sorption of organic contaminants to five types of plastic pellets: Implications for plastic marine debris. Environmental Science and Technology, 47, 1646-1654. 
Rochman, C. M., Manzano, C., Hentschel, B., Massey, L., Simonich, S., \& Hoh, E. (2013d). Polystyrene plastic: A source and sink for polycyclic aromatic hydrocarbons in the marine environment. Environmental Science and Technology, 47, 13976-13984.

Rochman, C. M., Hentschel, B. T., \& Teh, S. J. (2014a). Long-term sorption of metals is similar among plastic types: Implications for plastic debris in aquatic environments. PLOS One, 9, e85433.

Rochman, C. M., Lewison, R. L., Eriksen, M., Allen, H., Cook, A. M., \& Teh, S. J. (2014b). Polybrominated diphenyl ethers (PBDEs) in fish tissue may be an indicator of plastic contamination in marine habitats. Science of the Total Environment, 476, 622-633.

Rochman, C. M., Kurobe, T., Flores, I., \& Teh, S. J. (2014c). Early warning signs of endocrine disruption in adult fish from the ingestion of polyethylene with and without sorbed chemical pollutants from the marine environment. Science of the Total Environment, 493, 656--661.

Rochman, C. M., \& Boxall, A. B. A. (2014). Environmental relevance: A necessary component of experimental design to answer the question, "So what?" Integrated Environmental Assessment and Management, 10, 311-312.

Ross, P. S., \& Birnbaum, L. S. (2010). Integrated human and ecological risk assessment: A case study of persistent organic pollutants (POPs) in humans and wildlife. Human and Ecological Risk Assessment, 9, 303-324.

Rusina, T., Smedes, F., Klanova, J., Booij, K., \& Holoubek, I. (2007). Polymer selection for passive sampling: A comparison of critical properties. Chemosphere, 68, 1344-1351.

Ryan, P. G., Connell, A. D., \& Gardner, B. D. (1988). Plastic ingestion and PCBs in seabirds: Is there a relationship? Marine Pollution Bulletin, 19(4), 174-176.

Secretariat of the Convention on Biological Diversity. (2012). Impacts of marine debris on biodiversity. CBD technical series no. 67. http://www.thegef.org/gef/sites/thegef.org/files/ publication/cbd-ts-67-en.pdf.

Seki, M., Yokota, H., Maeda, M., Tadokoro, H., \& Kobayashi, K. (2003). Effects of 4-nonylphenol and 4-tert-octylphenol on sex differentiation and vitellogenin induction in medaka (Oryzias latipes). Environmental Toxicology and Chemistry, 22(7), 1507-1516.

Sinkonnen, S., \& Paasivirta, J. (2000). Degradation half-life times of PCDDs, PCDFs and PCBs for environmental fate modeling. Chemosphere, 40, 943-949.

Smedes, F., Geertsma, R. W., Van der Zande, T., \& Booij, K. (2009). Polymer-water partition coefficients of hydrophobic compounds for passive samplilng: Application for cosolvent models for validation. Environmental Science and Technology, 43, 7047-7054.

Takada, H. (2006). Call for pellets! international pellet watch global monitoring of POPs using beached plastic resin pellets. Marine Pollution Bulletin, 52(12), 1547-1548.

Tanaka, K., Takada, H., Yamashita, R., Mizukawa, K., Fukuwaka, M. A., \& Watanuki, Y. (2013). Accumulation of plastic-derived chemicals in tissues of seabirds ingesting marine plastics. Marine Pollution Bulletin, 69, 219-222.

Teuten, E. L., Rowland, S. J., Galloway, T. S., \& Thompson, R. C. (2007). Potential for plastics to transport hydrophobic contaminants. Environmental Science and Technology, 41(22), $7759-7764$.

Teuten, E. L., Saquing, J. M., Knappe, D. R., Barlaz, M. A., Jonsson, S., Björn, A., et al. (2009). Transport and release of chemicals from plastics to the environment and to wildlife. Philisophical Transactions of the Royal Society B, 364, 2027-2045.

Tien, C., Wu, W., Chuang, T., \& Chen, C. S. (2009). Development of river biofilms on artificial substrates and their potential for biomonitoring water quality. Chemosphere, 76, 1288-1295.

Tien, C., \& Chen, C. S. (2013). Patterns of metal accumulation by natural river biofilms during their growth and seasonal succession. Archives of Environmental Contamination and Toxicology, 64, 605-616.

Thompson, R. C., Olsen, Y., Mitchell, R. P., Davis, A., Rowland, S. J., John, A. W. G., et al. (2004). Lost at sea: Where is all the plastic? Science, 304, 838.

Thompson, R. C., Swan, S. H., Moore, C. J., \& vom Saal, F. S. (2009). Our plastic age. Philosophical Transactions of the Royal Society B, 364(1526), 1973-1976.

USEPA. (2013). Water: CWA methods-priority pollutants. http://water.epa.gov/scitech/ methods/cwa/pollutants.cfm. 
Van, A., Rochman, C. M., Flores, E. M., Hill, K. L., Vargas, E., Vargas, S. A., et al. (2011). Persistent organic pollutants in plastic marine debris found on beaches in San Diego, California. Chemosphere, 86, 258-263.

Vasseur, P., \& Cossu-Leguille, C. (2006). Linking molecular interactions to consequent effects of persistent organic pollutants (POPs) upon populations. Chemosphere, 63, 1033-1042.

Velzeboer, I., Kwadijk, C. J. A. F., \& Koelmans, A. A. (2014). Strong sorption of PCBs to nanoplastics, microplastics, carbon nanotubes, and fullerenes. Environmental Science and Technology, 48(9), 4869-4876.

Wagner, M., \& Oehlmann, J. (2009). Endocrine disruptors in bottled mineral water: Total estrogenic burden and migration from plastic bottles. Environmental Science and Pollution Research, 16(3), 278-286.

Wagner, M., \& Oehlmann, J. (2011). Endocrine disruptors in bottled mineral water: Estrogenic activity in the E-Screen. The Journal of Steroid Biochemistry and Molecular Biology, 127(1), 128-135.

Weijuan, L., Yougian, D., \& Zuyi, T. (2001). Americium(III) adsorption on polyethylene from very dilute aqueous solutions. Journal of Radioanalytical and Nuclear Chemistry, 250, 497-500.

Wu, B., Taylor, C. M., Knappe, D. R. U., Nanny, M. A., \& Barlaz, M. A. (2001). Factors controlling alkylbenzene sorption to municipal solid waste. Environmental Science and Technology, $35,4569-4576$.

Wurl, O., \& Obbard, J. P. (2004). A review of pollutants in the sea-surface microlayer (SML): A unique habitat for marine organisms. Marine Pollution Bulletin, 48(11), 1016-1030.

Xu, H., Vanhooren, H. M., Verbeken, E., Yu, L., Lin, Y., Nemery, B., et al. (2004). Pulmonary toxicity of polyvinyl chloride particles after repeated intratracheal instillations in rats. Elevated CD4/CD8 lymphocyte ratio in bronchoalveolar lavage. Toxicology and Applied Pharmacology, 194(2), 122-131.

Yamashita, R., Takada, H., Fukuwaka, M. A., \& Watanuki, Y. (2011). Physical and chemical effects of ingested plastic debris on short-tailed shearwaters, Puffinus tenuirostris, in the North Pacific Ocean. Marine Pollution Bulletin, 62(12), 2845-2849.

Yang, C. Z., Yaniger, S. I., Jordan, V. C., Klein, D. J., \& Bittner, G. D. (2011). Most plastic products release estrogenic chemicals: A potential health problem that can be solved. Environmental Health Perspectives, 119(7), 989.

Ye, S., \& Andrady, A. L. (1991). Fouling of floating plastic debris under Biscayne Bay exposure conditions. Marine Pollution Bulletin, 22, 608-613.

Zabaniotou, A., \& Kassidi, E. (2003). Life cycle assessment applied to egg packaging made from polystyrene and recycled paper. Journal Cleaner Production, 11(5), 549-559.

Zarfl, C., \& Matthies, M. (2010). Are marine plastic particles transport vectors for organic pollutants to the Arctic? Marine Pollution Bulletin, 60(10), 1810-1814.

Zettler, E. R., Mincer, T. J., \& Amaral-Zettler, L. A. (2013). Life in the "Plastisphere": Microbial communities on plastic marine debris. Environmental Science and Technology, 47, 7137-7146.

Zhuang, P., McBride, M. B., Xia, H., Li, N., \& Li, Z. (2009). Health risk from heavy metals via consumption of food crops in the vicinity of Dabaoshan mine, South China. Science of the Total Environment, 407(5), 1551-1561. 